\section{Donor Acknowledgments}

The Penn Museum gratefully acknowledges the support of the following supporters of the creation of the Middle East Galleries, opened April 2018, that this volume is companion to, or to the extended research work in the Middle East that the galleries display.

Naming Donors

Selz Foundation

William B. Dietrich Foundation

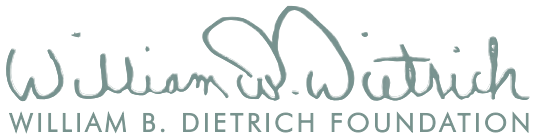

Support of Middle East Publications

The Hagop Kevorkian Fund, in honor of Ralph Minasian

Support of the Textile Display

The Coby Foundation

Ceby | тне сову Foundation, Ltid.

Leadership Support

Anonymous (1)

Meredith Dwyer Burke and Arthur J. Burke, C89, W89

Joanne H. Conrad, C79, PAR12, and William L. Conrad, PAR12

Alice L. George, Ph.D., GGS96

Peter G. Gould, Ph.D., LPS10, and Robin M. Potter, WG80/ PoGo Family Foundation
In memory of Sally Dreyfus Kalish, CW60, Athlete/Scholar Janet S. Klein, ED51, and Lew Klein, C49

Kowalski Family Foundation

Macquarie Holdings, Inc.

Elizabeth Ray McLean, C78

Andrew Moelis, C10

National Endowment for the Humanities

\section{Humanities}

The Pew Center for Arts \& Heritage

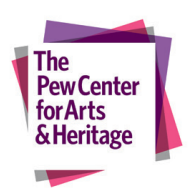

Gretchen P. Riley, CW70, PAR00, PAR04, and J. Barton Riley, W70, PAR00, PAR04

John Richard Rockwell, W64, WG66, PAR00

Jeannette and Jonathan Rosen

Kathryn and Sanford M. Sorkin, W67

Jill Topkis Weiss, C89, WG93, PAR19, and Jeffrey L. Weiss, PAR19

Charles K. Williams, II, Ph.D., GR78, HON87 

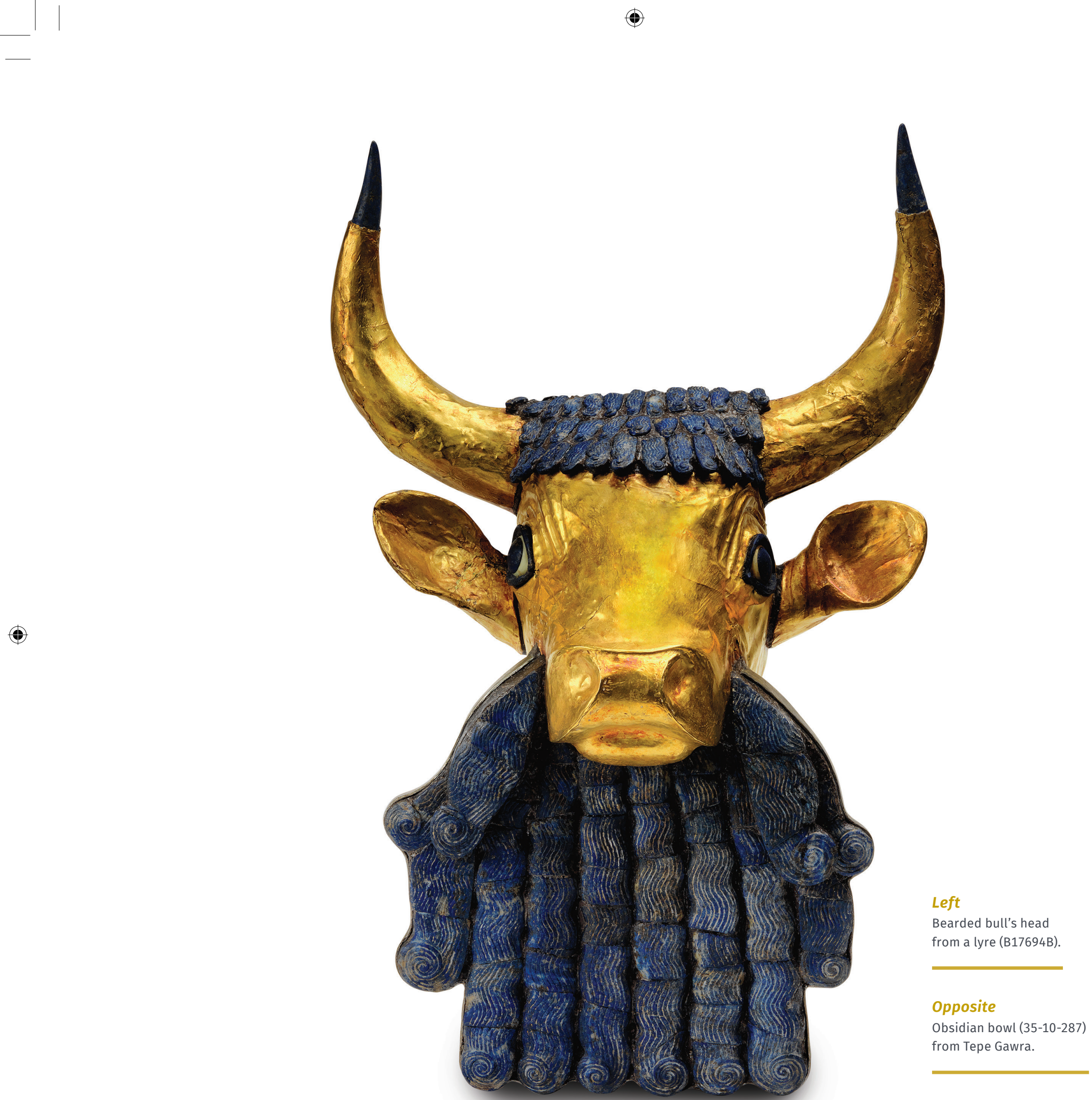